BIOKEMISTRI 17(1):51-56 (June 2005)

Available online at http://www.bioline.org. br/bk.

Abstracted online at www.ajol.info/journals/biokem

Printed in Nigeria
Rn international journal published by the

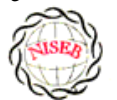

OVigerian \&ociety for \&̊xperimental Siology

\title{
Non-specific cell-mediated immunity in Nigerian children with uncomplicated malaria
}

\section{Ganiyu O. ARINOLA * ${ }^{1}$, Emmanuel I. UGWUJA ${ }^{1}$, Lekan S. SALIMONU ${ }^{1}$, Kayode S. ADEDAPO ${ }^{1}$ and Adeyinka G. FALUSI ${ }^{2}$}

\author{
${ }^{1}$ Immunology Unit, Department of Chemical Pathology, College of Medicine, University of Ibadan, \\ Ibadan, Nigeria. \\ ${ }^{2}$ Advance Institute of Medical Research and Training, College of Medicine, University of Ibadan, Oyo \\ State, Nigeria.
}

Received 13 September 2004

MS/No BKM/2004/024, (C) 2005 Nigerian Society for Experimental Biology. All rights reserved.

\begin{abstract}
Non-specific cellular immunity was determined in 59 Nigerian children aged between 1-9 years with uncomplicated malaria and 93 age-matched uninfected controls using percentage migration index (\%M.I) and Mantoux tuberculin skin test. The mean \%M.I (using malaria Pf 155 antigen) was significantly lower in malaria subjects compared with the controls $(p<0.05)$ while the mean diameter of tuberculin skin reaction (using Purified Protein Derivative of Mycobacterium butyricum) was significantly lower in children with uncomplicated malaria compared with the controls $(\mathrm{p}<0.05)$. The mean total white blood cell count $(\mathrm{TWBC})$ was also significantly reduced in the malaria subjects when compared with the controls $(\mathrm{p}<0.05)$. The results show that leucocytes of children with uncomplicated malaria exhibited effective adaptive immune response. This may help to combat initial contact with malaria parasites.
\end{abstract}

Key words: Migration index, uncomplicated malaria, children, immunity, Pf 155

*Author to whom all correspondence should be addressed.

E-mail: arinolaog@doctor.com; Tel: 08023451520 


\section{INTRODUCTION}

Malaria infection has been associated with great morbidity and mortality in children living in malaria endemic regions of the world (1-3) Malaria is considered uncomplicated if the asexual parasitaemia level is between 1000-2000 parasites per microliter of blood and a temperature of $38^{\circ} \mathrm{C}(2-4)$. Studies have shown that certain innate and immunological factors are responsible for the protection against malaria in children (1-6). Transplacental transfer of $\mathrm{IgG}$, foetal haemoglobin $(\mathrm{HbF})$ and milk diet deficient in para-aminobenzoic acid (PABA) are some of the factors that determines severity and prevalence of malaria in children $(2,5)$.

Macrophages produce radical oxygen intermediates, nitric oxides, tumour necrosis factor and interleukin 1 that activate the host defense mechanism against malaria $(5,6)$. Lymphocyte proliferation (7), red cell ingestion $(8,9)$ and cytokine production $(10,11)$ were earlier assessed in subjects with malaria. Enhanced ingestion of parasitized erythrocytes by phagocytes was found to be a common feature during acute malaria (12), however, leucocyte response to migratory lymphokine that is a critical step before ingestion was not determined $(12,13)$. The in vitro production of leucocyte migration inhibition factor (assayed as $\%$ M.I) by activated leucocytes has been accepted as an in vivo equivalent of delayed type hypersensitivity (DHS) (13-16). Two studies on leucocyte migration inhibition factor (L-MIF) in Indians with malaria were encountered $(17,18)$, and both produced contradicting results. Immunized Indians with no clinical symptoms of malaria showed significantly reduced \% M.I as compared to American/European controls (17). However, Sholapurkar et al (18) assessed $\%$ M.I as a measure of cell-mediated immunity in pregnant Indians with or without malaria parasitaemia. They reported raised \%M.I in pregnant Indian females with malaria especially in $3^{\text {rd }}$ trimester.

Most previous studies on cell-mediated immunity in patients with malaria concentrated on lymphocyte proliferation, red cell ingestion and cytokine production $(23,24)$ but these studies produced diverse results. None of these studies used antigen(s) from malaria parasite as stimulator. Moreover, percentage migration index is yet to be determined in Nigerian children with uncomplicated malaria. This study is thus designed to assay for \%M.I in Nigerian children with uncomplicated malaria, so as to ascertain their non-specific cell-mediated immunity.

\section{MATERIALS AND METHODS:}

Malarial subjects:

Blood samples from 152 children (80 males and 72 females) aged between 1-9 years $(4.24 \pm 2.88$ years of age) having temperature of $\geq 38^{\circ} \mathrm{C}$ were screened for the presence of Plasmodium parasite using 4\% Giemsa stain. They were recruited from Local Government Clinics in Inalende and Idi-Ogungun areas of Ibadan, Nigeria and Adeoyo State Hospital, Ibadan, Nigeria. All stages of malaria parasites were counted and the densities recorded as number of parasites per 200 WBCs. Their densities were converted to parasite per micro-liters blood assuming an average WBC count of $8000 / \mathrm{uL}$ (19).

\section{Controls:}

Ninety-three subjects without detectable bacteraemia, bacteriuria and malaria parasites served as controls and were considered for leucocyte migration inhibition factor assay.

\section{Bacteraemia:}

A standard bacteriological technique was adopted (20). Briefly, ten $\mathrm{ml}$ of blood samples collected by venepuncture was delivered into blood agar broth in a sterile glass bottle. . The content was thoroughly mixed and incubated at $37^{\circ} \mathrm{C}$ for 7 days. Each day the content was physically examined for turbidity. The turbid culture was inoculated into blood agar plate, chocolate agar and MacConkey plate and incubated at $37^{\circ} \mathrm{C}$ overnight. The characteristic appearance of the organism grown on each plate was noted and necessary biochemical tests were preformed and identification of colony was carried out as described by Collee (20).

\section{Bacteriuria:}

A standard bacteriuria technique (20) was adopted. Mid-stream urine samples collected in 
a sterile container from test- and controlsubjects were plated on both blood sugar and CLED (Cysteine Lactose Electrolyte Deficient) media. These cultured plates were incubated over night at $37^{\circ} \mathrm{C}$. Only cultures with bacterial count greater than 105 colonies $/ \mathrm{ml}$ of urine from two consecutive tests were considered.

\section{Enumeration of WBCs:}

This was done as described in a standard text (21). Total leucocytes were counted by the use of haemocytometer. Whole blood was diluted 1: 20 in Tuerk solution (2\% acetic acid tinted with gentian violet). With a capillary tube, this was applied on charged haemocytometer and counted under a light microscope at 40x objective. Cells found in all the five chambers were counted and final results multiplied by a factor of 40 . The result was expressed as number of cells per liter of blood.

\section{Leucocyte migration inhibition factor assay:}

The method described by Hudson and Hay (22) was adopted. Fifty-nine (59) subjects with malaria parasites and 93 controls without detectable malaria parasites, bacteriuria or bacteraemia were considered for L-MIF assay. Five $\mathrm{ml}$ of heparinised blood was mixed with equal volume of $3 \%$ dextran solution. This was allowed to stand at $37^{\circ} \mathrm{C}$ for 1 hour. The leucocyte-rich supernatant plasma was spun in a bench centrifuge at $300 \times \mathrm{x}$ for 10 minutes at room temperature. The harvested cells were washed three times in Kreb Ringer solution containing $15 \%$ foetal calf serum. They were counted in haemocytometer and adjusted to $1 \mathrm{x}$ $10^{8}$ cells/liter before being filled into capillary tubes which were spun at $850 \times \mathrm{x}$ for 10 minutes at room temperature. The capillary tubes were then cut at the packed cell medium interface. These were placed in a migration chamber and held in place by anchoring the sealed ends in silicon grease. The wells were filled with either medium $(15 \%$ foetal calf serum) or antigen-medium solution. Pf 155 (synthetic antigen located in the membrane of red blood cells infected with ring forms of Plasmodium falciparum) was used as stimulating antigen. The antigen-medium solution was prepared fresh at the time of use by mixing $0.1 \mathrm{ml}$ of Pf 155 with $9.9 \mathrm{ml}$ of $15 \%$ foetal calf serum. A drop of streptomycin was added to each well and incubated at $37 \%$ in $\mathrm{CO}_{2}$ incubator for $18 \mathrm{hrs}$. The migration area was projected onto transparent paper, outlined and area measured by counting the number of small squares enclosed on a graph pare. The percentage migration index (\%M.I) due to the antigen was calculated thus:

$\%$ M.I $=\mathrm{T} / \mathrm{C} \times 100 / 1$ where $\mathrm{C}$ is the area of migration in medium and $\mathrm{T}$ is the area of migration in antigen solution. The migration index value of $80 \%$ or less was taken as positive (22).

\section{Mantoux tuberculin skin test:}

Tuberculin-purified protein derivative $(0.1 \mathrm{ml})$ containing 5 tuberculin units was injected intradermally into the middle third of the anteromedial aspects of the left forearm of the subjects. Tuberculin purified protein derivative was administered with the aid of plastic insulin syringe and gauge 27 steel needle. The subjects were instructed not to scrub or rub the point of injection. The area of induration was defined by palpation and measured at 72 hours post injection in two perpendicular diameters using a metal tape. An induration measuring between zero to four $\mathrm{mm}$ was interpreted as negative, between five and nine $\mathrm{mm}$ as intermediate and ten $\mathrm{mm}$ or more as positive result (22).

\section{RESULTS}

The prevalence of bacteria in the urine and blood were slightly higher in subjects compared with the controls $(\mathrm{p}>0.05)$ as shown Table 1.

Table 1: Prevalence of bacteria in urine and blood of malaria subjects and the controls.

\begin{tabular}{|l|l|l|}
\hline & In Urine & In Blood \\
\hline Subjects & $10(12.3 \%)$ & $12(14.8 \%)$ \\
\hline Controls & $12(10.0 \%)$ & $15(12.5 \%)$ \\
\hline
\end{tabular}

There were significant reduction in the mean total white blood cell count (TWBC) and \%M.I in the subjects compared with the controls (Table 2). As shown in Table 2, Mantoux tuberculin skin reaction decreased significantly in malaria subjects compared with the controls $(\mathrm{p}<0.05)$. Table 3 shows that higher proportion $(94.6 \%)$ of children with malaria showed positive migration indices to $\mathrm{Pf} 155$ malarial antigen. 
Table 2: Total white blood cell counts, percentage migration indices and diameter of the Mantoux skin test of subjects with uncomplicated malaria compared wit the controls.

\begin{tabular}{|l|l|l|c|c|}
\hline & \multicolumn{1}{|c|}{$\begin{array}{c}\text { Controls } \\
\mathrm{n}=93\end{array}$} & \multicolumn{1}{|c|}{$\begin{array}{c}\text { Subjects } \\
\mathrm{n}=59\end{array}$} & $\mathrm{t}$ & $\mathrm{p}$ \\
\hline TWBC x $10^{9}$ cells/L & $9.96 \pm 2.69$ & $7.78 \pm 2.76$ & 3.31 & $<0.05$ \\
\hline$\%$ M.I & $60.92 \pm 16.99$ & $41.18 \pm 13.56$ & 7.55 & $<0.05$ \\
\hline $\begin{array}{l}\text { Mantoux skin diameter } \\
(\mathrm{mm})\end{array}$ & $12.3 \pm 0.4$ & $4.55 \pm 2.5$ & 4.13 & $<0.05$ \\
\hline
\end{tabular}

Table 3: Positivity index of \%M.I and Mantoux skin reaction in subjects with uncomplicated malaria compared with the controls.

\begin{tabular}{|l|c|l|}
\hline & $\%$ M.I & $\begin{array}{l}\text { Mantoux skin } \\
\text { reaction }\end{array}$ \\
\hline & + ve & + ve \\
\hline Subjects & $56(94.9 \%)$ & $14(14.6 \%)$ \\
\hline Controls & $75(81.4 \%)$ & $54(91.5 \%)$ \\
\hline
\end{tabular}

\section{DISCUSSION}

In this study, the observed fall in total white blood cell count in children with uncomplicated malaria compared with the controls may be an additional contributory factor to prevalence/severity of malaria parasitaemia among children. Previous authors reported agedependent decrease in transplacental transferred IgG and foetal haemoglobin (2,5). The mechanism of low TWBC in malaria subjects is unknown, although this could be due to sequestration of immunocompetent cells in the liver and spleen (23). It may also be as a result of reduced formation of white blood cells, since it has been found that the haemopoietic function of bone marrow is depressed in malaria subjects $(23,24)$. Leucocyte migration inhibition factor assay (determined in this study as \%M.I) is an in vitro correlates of delayed type hypersensitivity (DHS) $(13,14)$. Studies on the production of soluble mediator of leucocyte migration by antigen-stimulated-leucocytes from malaria subjects have been very limited and produced contrasting results. Ravindra et al (17) reported a significantly reduced \%M.I in immuned Indians with no clinical symptoms of malaria. In contrast, Sholapurkar et al (18) reported increased \%M.I in pregnant malaria subjects especially during their third trimesters.

The reduction in \%M.I in the malaria subjects observed in this study could be as a result of higher concentration of leucocyte migration inhibition factor produced by leucocytes despite the low number of these leucocytes. The in vivo significance of this is that leucocytes of subjects with uncomplicated malaria will move efficiently towards malaria parasites/antigens. It will be of interest in future to determine the subpopulation of leucocytes in children with uncomplicated malaria so as to point out which of these subpopulations causes the reduction in leucocyte count. Higher positivity index of $\%$ M.I $(94.9 \%)$ in children with uncomplicated malaria than the controls also support hyper secretion of L-MIF in malaria as. Reduced mean diameter of tuberculin skin reaction to PPD or reduced proportion of tuberculin skin positive reactors among children with uncomplicated malaria indicates depressed migration of leucocytes in these subjects to non-malarial antigen. This partially explains slightly higher rate of bacteraemia or bacteriuria in our subjects with malaria parasitaemia. The importance of these findings is that antigen specific adaptive immune response that keep malaria infection under control is maintained in children with uncomplicated malaria.

\section{Acknowledgement}

This study was supported by University of Ibadan, College Research Grant, 2000. We are grateful to the staff of Adeoyo State Hospital and Local Government Health Centers (at Ayeye, Oniyanrin and Idi-Ogungun) Ibadan, 
Oyo State, Nigeria. Messrs Odetunde, A.B. and Adebiyi, E.O. and Mrs Okiwelu, H.O. for their technical assistance.

\section{REFERENCES}

1. Hawking F. (1983) Milk, para-aminobenzoic acid abd malaria (Plasmodium berghei). Br. Med. J. I: 1201-1202.

2. Nardin E.H, Nussenzweig R.S, Bryan J.H and McGregor I.A. (1980) Congenital transfer of antibody against malaria sporozoites detected in Gambian infants. Amer.J.Trop.Med.Hyg. 30: 1159-1163.

3. Friedman M.J and Trager W. (1981) The biochemistry of resistant malaria. Scientific Amer. 244:113-120.

4. Posvol G and Wilson RJM. (1982) The interaction of malaria parasites with red blood cells. Br. Med. J. 30:113-140.

5. Weatherall D.J. (1987) Common genetic disorders of red cells and the malaria hypothesis. Ann.Trop. Med. Parasitol. 81:539-548.

6. W.H.O. (1989) Glucose- 6- phosphate dehydrogenase deficiency. Bull. WHO 67: 601611.

7. Fievet N, Ringwald P, Bikii J, Dubois B, Maubert B, Le Hasran J.Y, Cot $M$ and Deloron P. (1996) Malaria cellular immune responses in neonates from Cameroun. Par. Immunol.. 21: 319-329.

8. Loose L.D. (1984) Characterization of macrophages dysfunction in rodent malaria. $J$. Leucocyte Biol. 36:703-718.

9. Eling M.W, Jerusalem C.R and HeinenBoores U. (1984). Role of macrophage in the pathogenesis of endomyocardial fibrosis in murine malaria. Trans. Roy. Soc. Med. Hyg. 78: 43-48.

10. Day N.P, Hien T.T, Shollaardt T, Lo P.P, Chiong L.V, Chao T.T, Mai N.T, Phu N.H, Sinh D.X. White N.J and Ho M. (1999) The prognostic and pathophysiological role of pro and anti-inflammatory cytokines in severe malaria. J. Infect. Dis. 180:1288-1297.

11. Hirunpeteharat, Kinkalman, Clark I.A and Good M.F. (1999) Malaria parasitespecific Th-1 like ells simultaneously reduces parasitaemia and promote disease. Parasite Immunol. 21:319-329.

12. Leitner W.W and Kryzch U. (1997) Plasmodium falciparum malaria blood stage parasites prefentially inhit macrophages with high phagocytic activity. Parasite Immunol. 19: 103-110.

13. Arinola O.G and Salimonu L.S. (1999) Leucocytes migration inhibitory factor assay in Nigerians with urinary schistosomiasis. W.A.J.M. 18: 101-105.

14. Oyeyinka G.G, Salimonu L.S and Ladipo O.A. (1996) Leucocyte migration inhibition studies and neutrophil cell function during ageing in Nigerian. Mech. Ageing Dev. 24: 8393.

15. Calandra T, Bernhager I, Metz .N, Spiegel L.A, Bacher M, Donally T, Cerami A, Bucola R. (1995) MIF as a glucocorticoid-induced modulator of cytokine production. Nature. 377: 68-71.

16. Bacher M. (1996) An essential regulatory role of MIF in T cell activation. Proc. Natl. Acad. Sci. U.S.A. 93: 7849-7854.

17. Ravindran B, Sharma B, Pillai C.R and Hussain Q.Z. (1983) Leucocyte migration inhibition test in human Plasmodium vivax malaria. J.Trop. Med. Hyg. 86: 207-211.

18. Sholarpurkar L.S, Mahajan R.C, Gupta A.N and Wangoo A. (1990) Cellular immunity in pregnant and non-pregnant women with mamarial infection. Asia Oceania J. Obstet. Gynaecol. 16: 27-32.

19. Rooth I, Perlmann H and Bjorkman A. (1991) Plasmodium falciparum re-infection in children from holoendemic are in relation to 
seroacticities against oligopeptides from malaria antigens. Amer. J. Trop. Med. Hyg.. 45: 309318.

20. Collee J.G. (1986) A guide to microbial infections, pathogenesis, immunity, laboratory diagnosis and control. In Medical Microbiology. $15^{\text {th }}$ Ed. Pp 234.

21. Dacies J.V and Lewis S.M. (1984) Practical Haematology, $\quad 6^{\text {th }}$ edition. Churchill, Livingstone, London. Pp: 45-52.

22. Hudson L and Hay F.C. (1988) Practical Immunology. Blackwell Scientific Publication.
Oxford, London. Edinburgh. Melbourne. Pp: 3139

23. Angulo I, Rodriguez R, Garia B, Medina M, Navarro J and Subiza J.L. (1995) Involvement of nitric oxide in marrow derived natural suppressor activity, its dependence on IFN-gamma. J. Immunol. 155: 15-26.

24. Rocklin R.E, Bendizen K, Greinedr D. (1980) Mediator of immunity. Lymphokines and monokines. Adv. Immunol. 29: 55-136. 